\title{
Evaluation of Selected Methods of Mitigation of Media Flow Maldistribution Impact in Finned Cross-flow Heat Exchangers*
}

\author{
T. Bury**, J. Składzień \\ Institute of Thermal Technology, Silesian University of Technology \\ Konarskiego 22, 44-100, Gliwice, Poland \\ E-mail: tomasz.bury@polsl.pl
}

\begin{abstract}
The up to date investigations concerning media flow maldistribution in heat exchangers have shown that this phenomena could significantly affect the efficiency of heat exchanger operation. Analyses of a non-uniform gas inlet to cross-flow finned heat exchangers are conducted by means of numerical simulations and experiments for over ten years at the Institute of Thermal Technology of the Silesian University of Technology. This paper summarizes works aimed in evaluation of different methods of mitigating a negative impact of the non-uniform gas inflow on heat exchanger performance.
\end{abstract}

Keywords: Cross-flow heat exchangers; media flow maldistribution; experimental analyses; numerical simulations.

\section{Introduction}

Cross-flow heat exchangers having cores in the form of a bunch of pipes ribbed with plate rectangular or elliptic ribs belong to the most popular such devices in industry. Small size, low weight and high efficiency are the advantages of these heat exchangers.

Typical thermodynamic analysis of this type of heat exchanger is conducted applying several simplifying assumptions, such as uniform flow of media through the exchanger, heat transfer coefficients determined for an average temperature of a medium, and one-dimensional heat transfer. These assumptions are rarely fulfilled in reality, so it is important to know to what extent certain assumption affects the results.

The problem of a non-uniform flow of media in a ribbed cross-flow water cooler is investigated for almost 10 years in the Institute of Thermal Technology of the Silesian University of Technology. Initially only numerical researches were conducted which were later supplemented with experimental analyses also. Measurements have been realized on a specially designed testing station (see Fig. 1) for determination of the form and scope of the air inflow non-uniformity. The experimental data have been supplied to the in-house computer code HEWES and the impact of the non-uniformity has been evaluated (Piątek, 2003).

The researches realized in the next steps, also for other heat exchangers of the same type, allowed for validation of the HEWES code and have confirmed initial observations: non-uniform flow of media may significantly affect the heat exchanger efficiency - the deterioration of the total heat flow rate transported in the device have reached up to $20 \%$, while average values are about $15 \%$ for analyzed cases (Bury, 2012).

There are many works, both experimental and numerical, considering only the flow maldistribution impact on the hydraulic efficiency of heat exchangers. Anjun with his co-workers investigated the influence of header configuration on the non-uniformity range (Anjun et al.,
2003). The numerical results presented in Wen and $\mathrm{Li}$ (2004) indicate that the improved header configuration can effectively improve the performance of a fin-and-tube type heat exchanger. An experimentally determined flow maldistribution for a plate fin-and-tube heat exchanger has also been described in (Hoffmann-Vocke et al., 2009), but the authors have not considered its impact on the heat exchanger thermal efficiency. This group of authors has presented in (Hoffmann-Vocke et al., 2011) even more detailed work, but still only the hydraulic analysis of the considered heat exchanger is presented.

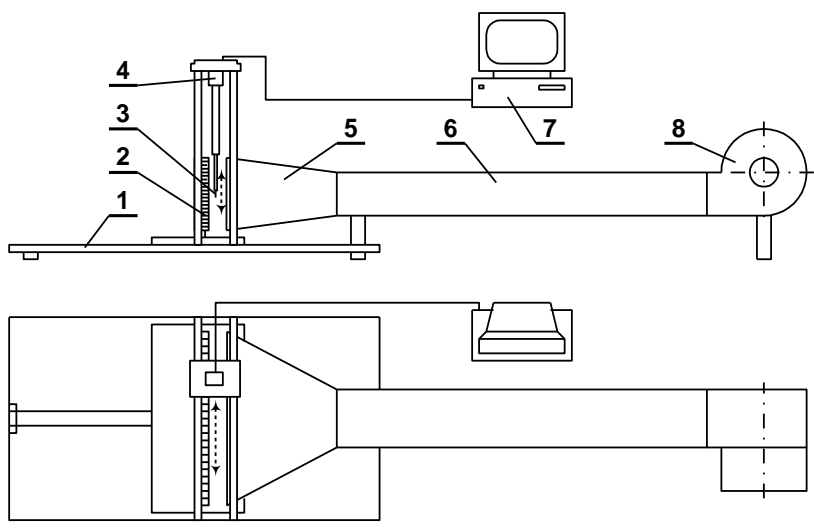

Figure 1. Testing station - the air supply module (1 support plate, 2 - heat exchanger, 3 -thermoanemometric sensor, 4 -measuring probe, 5 -diffuser, 6 -channel, 7 control computer, 8 -fan).

Experimental analyses considering maldistributions of the agents flow through the heat exchangers and dealing with thermodynamic effects are rare. Mueller (1987) concludes about the major significance of flow maldistributions on heat exchangers performance. Based on the study of gross flow maldistribution in an experimental electrical heater Lalot et al. (1999) present the effect of

${ }^{*}$ This paper is an updated version of a paper published in the CPOTE 12 proceedings. It is printed here with permission of the authors and organizers. 
flow non-uniformity on the performance of heat exchangers. The original fluid distribution is applied to heat exchangers (condensers, counterflow and cross-flow heat exchangers), and it is shown that gross flow maldistribution leads to a loss of effectiveness of about $7 \%$ for condensers and counterflow heat exchangers, and up to $25 \%$ for crossflow exchangers. Similar effects have been observed by Luo et al. (2001) who indicate that the non-uniformity influences the efficiency of heat exchangers to a large extent. Berryman and Russell (1987) have studied flow maldistribution across tube bundles in air-cooled heat exchangers. Their experimental results have detected thermal degradation up to $4 \%$, which is much less than in previously cited works. Meyer and Kröger (1998) concluded the minor effects - up to $5 \%$ - of this phenomenon also.

Very complex researches have been realized by teams from Indian Institute of Technology - Madras and Lund University of Technology. These works concern plate-type heat exchangers. The numerical model of a one-pass plate heat exchanger has been elaborated first for hydraulic analyses of a flow maldistribution impact (Shrihari et al., 2005) and next it was arranged for multi-pass units (Shrihari and Das, 2008). An experimental investigation has been also carried out to find the flow and the pressure difference across the ports to channels in plate heat exchangers (Rao et al., 2006). More recently this research team realized thermal analysis also. The single-blow transient test technique based on axial dispersion model was proposed for the determination of both heat transfer coefficient and axial dispersion coefficient in plate heat exchangers. The experimental analysis presented in (Shaji and Das, 2010) deals with the effect of flow maldistribution on the transient temperature response for U-type plate heat exchangers. The experiments are carried out with uniform and non-uniform flow distributions for various flow rates and two different numbers of plates.

According to Zhang (2009) the inlet and outlet duct geometry in an air to air compact heat exchanger is always irregular. Such duct placements usually lead to a nonuniform flow distribution on the core surface. The author used a CFD model to predict the flow distribution and next calculated the heat exchange effectiveness and the thermal performance deterioration factor with a finite difference scheme. Experiments were performed to validate the flow distribution and heat transfer model. The results indicate that when the channel pitch is below $2.0 \mathrm{~mm}$, the flow distribution is quite homogeneous and the thermal deterioration due to flow maldistribution can be neglected. However, when the channel pitch is larger than $2 \mathrm{~mm}$, the maldistribution is quite large and a 10-20\% thermal deterioration factor could be found.

This short review of available results concerning the impact of media flow maldistribution in heat exchangers shows that this problem could be significant. The results obtained by the authors and presented partially in (Bury et al., 2009; Bury, 2012) are comparable with outcomes of other researchers. There is however still some gap in experimental works concerning improvement of efficiency of heat exchangers operating in non-uniform media flow conditions. Numerical investigations of this problem could be found in (Lee \& Oh, 2004) for example.

Four hypotheses concerning the possibility of increasing the efficiency of the heat exchanger working in a nonuniform media flow conditions have been also reviewed during these studies. The obvious hypothesis (marked as H1) assumes increasing of the total heat flow rate transported in the heat exchanger as the effect of making a medium flow uniform. The other hypotheses assume that the efficiency of the heat exchanger may be increased if:

- the air inflow will be blocked to the regions of the heat exchanger of minor or negligible fraction in the total heat transfer while simultaneously increasing air flow through the remaining parts of the device - H2 (Bury et al., 2009),

- the air flow turbulence will be increased, as the turbulent heat transfer coefficient is much higher than laminar - H3 (Bury et al., 2010),

- the air inflow will be directed to those regions of the heat exchanger where the heat transfer is more efficient (near to the water inlet header for example) - H4 (Bury et al., 2010).

All the above mentioned hypotheses have been verified both numerically and by means of experiments, and of course the results of measurements have the highest priority during analysis.

The aim of this work is to summarize the verification of the hypotheses H1-H4 and check out one more. In many cases there are no technical possibilities to undertake actions in order to realize the assumptions of hypotheses $\mathrm{H} 1$ - H4. The authors postulate that application of a special ribbing structure may bring some positive effects. This needs only an intervention in the construction of the heat exchanger: the ribbing structure should be designed for the given air flow conditions. This hypothesis has been marked as $\mathrm{H} 5$ and its verification is the subject of this paper.

\section{Experimental Setup \\ 2.1 Testing Station and Measuring Procedure}

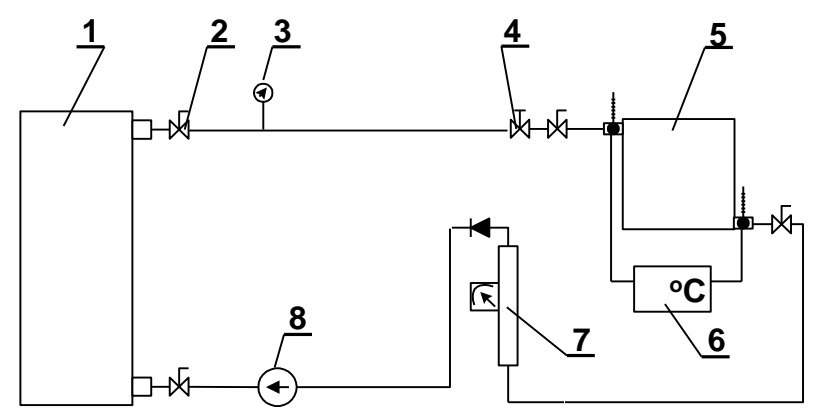

Figure 2. Testing station - the hot water supply module (1 - electric heater, 2 - cut-out valve, 3 - manometer, 4 control valve, 5-heat exchanger, 6 - temperature measuring system, 7 -flow meter, 8 - pump).

Verification of hypotheses by means of measurements has become possible after modernization of the testing station and installing a hot water supply module - see Fig. 2. The air supply module originally was a special testing station constructed during realization of the project (Piątek, 2003) for determination of a form and scope of the air inflow non-uniformity. The main element of the measuring system is a thermoanemometric sensor installed into a measuring probe whose shifting is controlled by a computer. It allows the determination of the velocity and temperature fields of the air at the exchanger inlet and outlet. The modernization of the experimental facility extended the possibilities of the measuring system which allows for acquisition of the following parameters at the 
moment: total air volumetric flow, the water volumetric flow rate, inlet and outlet water temperature, distribution of the air velocity and temperature at the inlet and outlet of the heat exchanger.

The measurement of the air temperature and velocity distributions need the measuring task to be defined in the form of an input file for the program controlling the measuring probe work. The time constant of the measurement and the number of measurements realized in each node should be entered in the file. A regular measuring net of 196 nodes has been used for measurements. Such a net divides the whole measuring cross section into identical rectangles in the middle of which the measuring nodes are localized. The measuring program is being started after steady state conditions are achieved.

The heat exchanger capacity can be determined as the heat flow rate transferred in the exchanger computed from the air and the water sides. The energy balances for air and water flows describing the media enthalpy decrease (increase) are as follow:

$$
\begin{aligned}
& \dot{Q}_{a}=\dot{V}_{a} \cdot \rho_{a} \cdot c_{p a} \cdot\left(T_{a, \text { out }}-T_{a, \text { in }}\right) \\
& \dot{Q}_{w}=\dot{V}_{w} \cdot \rho_{w} \cdot c_{p w} \cdot\left(T_{w, \text { in }}-T_{w, \text { out }}\right)
\end{aligned}
$$

The air density $\rho_{\mathrm{a}}$ has been calculated using the ideal gas law for the absolute pressure and the air average temperature at the inlet to the exchanger. The density of water $\rho_{\mathrm{w}}$ has been assumed according to thermodynamic tables for the outlet temperature.

\subsection{Analyzed heat exchangers}

There were three standard heat exchangers investigated during realization of this work. All of them were cross-flow plate fin and tube water coolers. A general arrangement and dimensions of these heat exchangers as well as the shape of the recurrent elements are presented in Fig. 3. The HE-1 heat exchanger is a typical car cooler (Skoda Favorit 135L) with the core having the form of 2 row pipe bundle (15 cylindrical pipes ribbed with plate fins in each row, 380 fins on each pipe) made of aluminum. The HE-2 and HE-3 heat exchangers are made by the GEA Heat Exchangers Company with the cores made of elliptical pipes (one row of 10 pipes in the HE-2 and two rows of 10 pipes in HE-3) ribbed with plate fins made of steel.

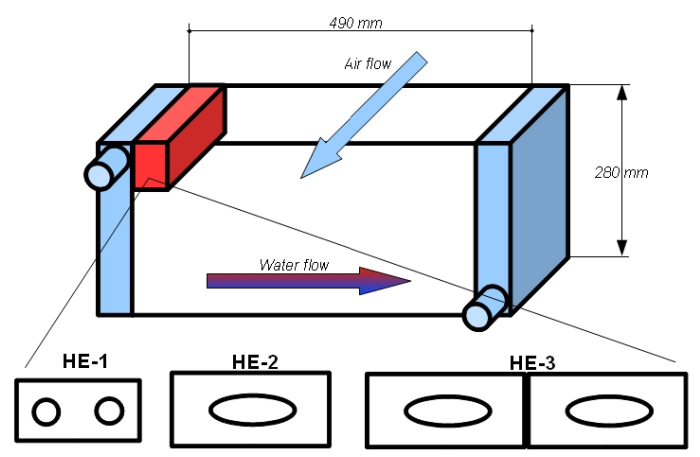

Figure 3. Sketch of the arrangement, dimensions and the shape of the recurrent elements of the analyzed heat exchangers.

\subsection{Reference measurements}

The reference measurements have been realized without any elements or actions aimed to improve the exchangers' efficiencies. The purpose of these measurements was to determine the heat flow rates assumed further as the reference values during the hypotheses verification. These measurements allowed also the identification of the areas of the heat exchangers where the heat transfer was significantly lower. Selected results of the reference measurements have been gathered in Table 1 and results of the total heat transfer rates for these experimental data are presented in Table 2 .

Table 1. Selected results of the reference measurements for the HE-1 unit.

\begin{tabular}{|c|c|c|c|c|c|c|}
\hline $\begin{array}{c}\text { Measu- } \\
\text { rement } \\
\text { No. }\end{array}$ & $\begin{array}{c}V_{w} \\
\mathrm{dm}^{3} / \mathrm{min}\end{array}$ & $\begin{array}{c}V_{a} \\
\mathrm{~m}^{3} / \mathrm{h}\end{array}$ & $\begin{array}{c}T_{a, \text { in }} \\
{ }^{\circ} \mathrm{C}\end{array}$ & $\begin{array}{c}T_{a, \text { out }} \\
{ }^{\circ} \mathrm{C}\end{array}$ & $\begin{array}{c}T_{w, \text { in }} \\
{ }^{\circ} \mathrm{C}\end{array}$ & $\begin{array}{c}T_{w, \text { out }} \\
{ }^{\circ} \mathrm{C}\end{array}$ \\
\hline HE-1/1 & 27,0 & 5600 & 34,6 & 41,2 & 49,8 & 43,9 \\
\hline HE-1/2 & 27,0 & 5600 & 33,4 & 46,8 & 68,9 & 56,7 \\
\hline HE-1/3 & 27,0 & 5600 & 34,2 & 54,3 & 86,4 & 67,9 \\
\hline HE-1/4 & 27,0 & 3000 & 33,9 & 44,5 & 49,7 & 44,5 \\
\hline HE-1/5 & 27,0 & 3000 & 33,8 & 55,0 & 69,2 & 58,7 \\
\hline HE-1/6 & 27,0 & 3000 & 34,5 & 66,4 & 88,0 & 72,2 \\
\hline
\end{tabular}

Table 2: Selected results of calculations for the reference measurements for the HE-1 unit.

\begin{tabular}{|c|c|c|c|}
\hline $\begin{array}{c}\text { Measurement } \\
\text { No. }\end{array}$ & $\begin{array}{c}\dot{Q}_{a} \\
\mathrm{~kW}\end{array}$ & $\begin{array}{c}\dot{Q}_{w} \\
\mathrm{~kW}\end{array}$ & $\begin{array}{c}\mathrm{NU}_{\text {ave. }} \\
\%\end{array}$ \\
\hline $\mathrm{HE}-1 / 1$ & 11,62 & 11,03 & 26,5 \\
\hline $\mathrm{HE}-1 / 2$ & 23,54 & 22,61 & 25,8 \\
\hline $\mathrm{HE}-1 / 3$ & 35,14 & 34,08 & 25,6 \\
\hline $\mathrm{HE}-1 / 4$ & 10,24 & 9,72 & 22,9 \\
\hline $\mathrm{HE}-1 / 5$ & 19,91 & 19,42 & 24,1 \\
\hline $\mathrm{HE}-1 / 6$ & 29,95 & 29,11 & 23,5 \\
\hline
\end{tabular}

The non-uniformity parameter NU (the last column in Table 2) has been defined in order to provide a quantitative description of the received results. This parameter is understood as the ratio of the difference between a real mass flow rate in the given measuring field $\dot{m}_{r, i}$ and the uniform mass flow rate $\dot{m}_{u}-$ see Eq. 3 . The uniform mass flow rate of the air has been derived assuming that the total mass flow rate of the air spreads equally across all measuring fields. The average value of the non-uniformity parameter was a criterion when comparing the measuring series.

$N U=\left|\frac{\dot{m}_{r, i}-\dot{m}_{u}}{\dot{m}_{u}}\right| \cdot 100 \%$

One can observe that the heat exchanger capacity calculated as the air enthalpy increase is higher than calculated as the water enthalpy drop. The reason of this is unavailability of taking into account a real volumetric flow rate of air flowing through the heat exchanger - there are some leaks in the installation but it is impossible to assess them.

An uncertainty in determining the heat exchanger capacity as the water enthalpy drop can be evaluated considering measurement errors. Applying the uncertainty (error) propagation law and taking into account that water 
flow rate and water temperatures are measured with some errors the following expression can be written:

$$
\Delta \dot{Q}_{w}=\sqrt{\left(\frac{\partial \dot{Q}_{w}}{\partial V_{w}}\right)^{2}\left(\delta V_{w}\right)^{2}+\left(\frac{\partial \dot{Q}_{w}}{\partial \Delta t_{w}}\right)^{2}\left(\delta \Delta t_{w}\right)^{2}}
$$

Taking into account the errors of water flow meter $\delta V_{w}=$ $\pm 1 \mathrm{dm}^{3} / \mathrm{min}$ and water temperature difference $\delta \Delta t_{w}= \pm 0,1$ $\mathrm{K}$ the maximum uncertainty of the heat exchanger capacity reaches $3,7 \%$ with the average value of $3,1 \%$.

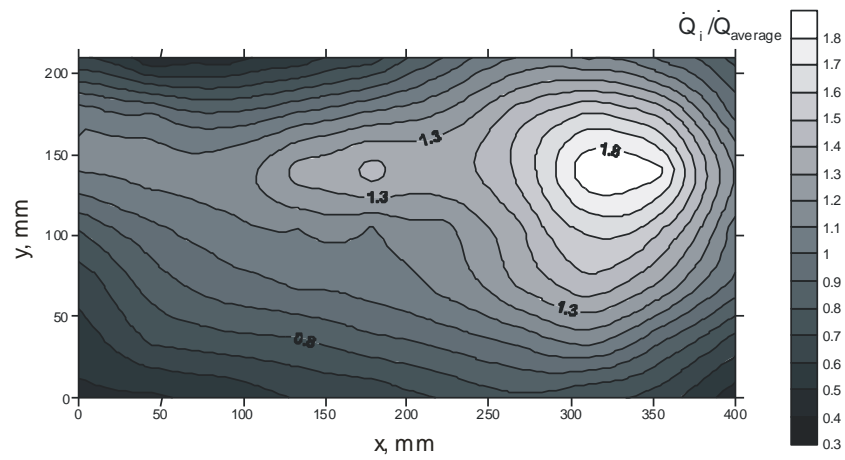

Figure 4. Distribution of the relative heat transfer rates in the exchanger cross section for the HE-1/1 measurement ( $Q_{i}$ heat transfer rate for the $i$-th measuring field, $Q_{\text {average }}$ area weighted average value of the heat transfer rate).

The air inlet and outlet velocity and temperature distributions are one of the most important experimental results. The distribution of the average heat transfer rates from water to air in the specified measuring fields has been elaborated based on the mentioned earlier distributions of the air velocity and temperature - this distribution for the HE-1/1 measurement is shown in Fig. 4. Such distribution is the basis for identification of the areas of the minor heat transfer.

\section{Results of analyses}

3.1 General comments on verification of hypotheses H1, $\mathrm{H} 2, \mathrm{H3}$ and $\mathrm{H} 4$

The hypotheses $\mathrm{H} 1$ - H4 have been investigated for the HE-1 heat exchanger (the car cooler) only. The evaluation of results has been made upon values of the relative differences between the total heat transfer rates obtained during the reference measurements and the verifying measurements. The total heat transfer rates have been calculated as the water enthalpy drop in every case.

The first hypothesis assumes the possibility of improving the efficiency of the exchanger by making the air inlet to the exchanger more uniform. Decrease of the air inflow non-uniformity has been realized by installation of filters before the diffuser, as it was mentioned before. The two types of wire nets and the perforated metal sheet have been applied, as shown in Fig. 5.

The filters placed in the air flow channel cause raising the pressure drop and change of the fan capacity. This of course has been taken into account while analyzing the experimental data. Selected results of analyses regarding verification of the hypothesis 1 are gathered in Table 3 .

The second hypothesis assumes the possibility of improving the heat exchanger efficiency as a result of an exclusion of these areas of the exchanger where the heat transfer is less intensive. These areas have been localized in the way described in subsection 2.3. It has been assumed that the air inflow to the areas with the relative heat flow rate equal or less than $30 \%$ will be blocked. These areas have been localized at the border of the exchanger for all analyzed cases. The results of verification are presented in Table 4.

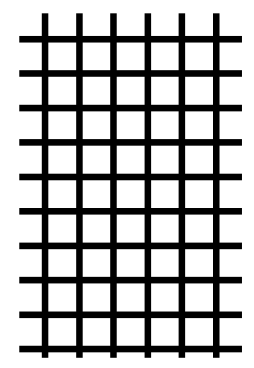

S1

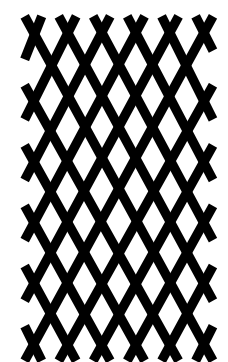

S2

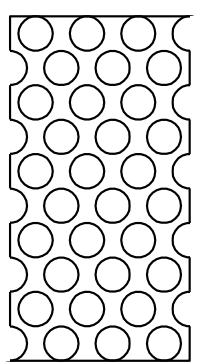

S3
Figure 5. View of the applied filters.

Table 3. Hypothesis 1 verification - results.

\begin{tabular}{|c|c|c|c|c|c|}
\hline $\begin{array}{c}\text { Measurement } \\
\text { No. }\end{array}$ & $\begin{array}{c}T_{w, \text { in }} \\
{ }^{\circ} \mathrm{C}\end{array}$ & $\begin{array}{c}T_{w, \text { out }} \\
{ }^{\circ} \mathrm{C}\end{array}$ & $\begin{array}{c}\dot{Q}_{w} \\
\mathrm{~kW}\end{array}$ & $\begin{array}{c}\mathrm{NU}_{\text {ave. }} \\
\%\end{array}$ & $\begin{array}{c}\delta \mathrm{Q} \\
\%\end{array}$ \\
\hline $\mathrm{HE}-1 / 1 / \mathrm{H} 1 / \mathrm{S} 1$ & 51,1 & 45,1 & 11,24 & 26,00 & 1,4 \\
\hline $\mathrm{HE}-1 / 1 / \mathrm{H} 1 / \mathrm{S} 2$ & 51,6 & 45,5 & 11,42 & 28,51 & 3,4 \\
\hline $\mathrm{HE}-1 / 1 / \mathrm{H} 1 / \mathrm{S} 3$ & 51,7 & 45,5 & 11,61 & 24,55 & 5,1 \\
\hline $\mathrm{HE}-1 / 2 / \mathrm{H} 1 / \mathrm{S} 3$ & 69,5 & 56,7 & 23,85 & 24,43 & 5,5 \\
\hline $\mathrm{HE}-1 / 3 / \mathrm{H} 1 / \mathrm{S} 3$ & 89,1 & 69,6 & 36,06 & 24,45 & 5,8 \\
\hline $\mathrm{HE}-1 / 4 / \mathrm{H} 1 / \mathrm{S} 3$ & 49,2 & 45,1 & 7,61 & 21,84 & 6,8 \\
\hline $\mathrm{HE}-1 / 5 / \mathrm{H} 1 / \mathrm{S} 3$ & 69,3 & 58,0 & 20,88 & 22,05 & 7,5 \\
\hline $\mathrm{HE}-1 / 6 / \mathrm{H} 1 / \mathrm{S} 3$ & 88,7 & 71,7 & 31,38 & 21,67 & 7,8 \\
\hline
\end{tabular}

Table 4. Hypothesis 2 verification - results.

\begin{tabular}{|c|c|c|c|c|c|}
\hline $\begin{array}{c}\text { Measure- } \\
\text { ment No. }\end{array}$ & $\begin{array}{c}\text { Numbers of } \\
\text { inactive } \\
\text { measuring } \\
\text { fields }\end{array}$ & $\begin{array}{c}T_{w, \text { in }} \\
{ }^{\circ} \mathrm{C}\end{array}$ & $\begin{array}{c}T_{w, \text { out }} \\
{ }^{\circ} \mathrm{C}\end{array}$ & $\begin{array}{c}\dot{Q}_{w} \\
\mathrm{~kW}\end{array}$ & $\begin{array}{c}\delta \mathrm{Q} \\
\%\end{array}$ \\
\hline $\mathrm{HE}-1 / 1 / \mathrm{H} 2$ & $\begin{array}{c}1,2,10,61, \\
62\end{array}$ & 49,6 & 43,8 & 10,94 & $-0,8$ \\
\hline $\mathrm{HE}-1 / 2 / \mathrm{H} 2$ & $1,2,10,61$ & 68,9 & 56,8 & 22,50 & $-0,5$ \\
\hline $\mathrm{HE}-1 / 3 / \mathrm{H} 2$ & $1,2,10,61$ & 87,8 & 69,7 & 33,64 & $-1,3$ \\
\hline $\mathrm{HE}-1 / 4 / \mathrm{H} 2$ & $1,2,61,62$ & 49,5 & 44,3 & 9,68 & $-0,4$ \\
\hline $\mathrm{HE}-1 / 5 / \mathrm{H} 2$ & $1,2,61,62$ & 69,5 & 59,0 & 19,48 & 0,3 \\
\hline $\mathrm{HE}-1 / 6 / \mathrm{H} 2$ & $1,2,61,62$ & 88,8 & 73,1 & 28,94 & $-0,6$ \\
\hline
\end{tabular}

The way of blocking the air inflow (assumed due to technical possibilities) caused only some limitation of the air flow through the considered measuring field. In reality, some air will still flow into the field from the space between ribs. So, the conditions for proper verification of the assumed hypothesis has not been fulfilled. The effect of this situation is very unambiguous results (see Table 4).

The hypothesis H3 assumed that the heat transfer in the analyzed heat exchanger can be improved if the air inflow to the device were more turbulent. Unfortunately, the experimental verification of the $\mathrm{H} 3$ hypothesis has failed the results indicate a decrease in the total heat transfer rate, as shown in Table 5. The main reason for this situation was the technical problems with the spiral insertions (Fig. 6) designed to increase the turbulence. Strong vibrations of these inserts have limited the measurements for the smallest air flow rates only. Moreover, without a detailed CFD analysis it could not be determined whether the turbulence really increased. 


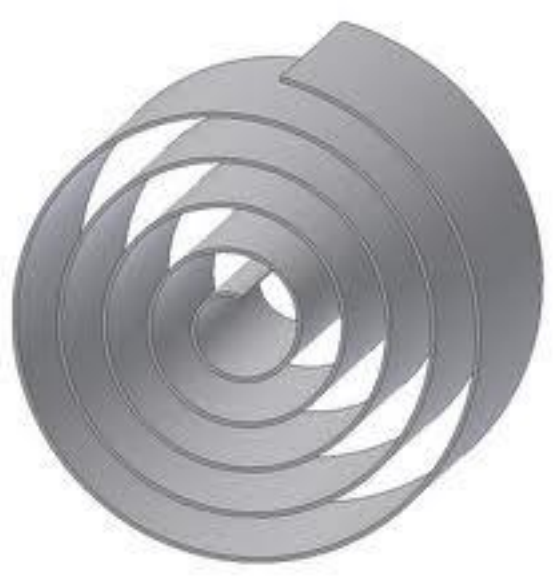

Figure 6. View of the spiral insertion for intensifying the turbulence of the air inflow.

Table 5. Hypothesis 3 verification - selected results.

\begin{tabular}{|c|c|c|}
\hline Measurements & $\begin{array}{c}\dot{Q}_{w} \\
\mathrm{~kW}\end{array}$ & $\begin{array}{c}\delta \mathrm{Q} \\
\%\end{array}$ \\
\hline $\mathrm{HE}-1 / 4 / \mathrm{H} 3$ & 9,35 & $-3,8$ \\
\hline $\mathrm{HE}-1 / 5 / \mathrm{H} 3$ & 18,35 & $-5,5$ \\
\hline $\mathrm{HE}-1 / 6 / \mathrm{H} 3$ & 26,84 & $-7,8$ \\
\hline
\end{tabular}

The H4 hypothesis assumes that some increase in the total heat transfer rates may be achieved by forcing the air flow to those areas of the heat exchanger where the heat transfer is more intensive, for example to the hot water inlet header area. The air inflow was modelled using insertions in the form of plain metal sheets mounted before the diffuser inlet. Two measuring series have been realized: S1 - more air has been directed to the region of high heat transfer rates ratio (see Fig. 4); S2 - more air has been directed to the hot water inlet header region (where the temperature difference between flowing media is high).

Table 6. Hypothesis 4 verification - results.

\begin{tabular}{|l|c|c|l|c|c|}
\hline Measurement & $\begin{array}{c}\dot{Q}_{w} \\
\mathrm{~kW}\end{array}$ & $\begin{array}{c}\delta \mathrm{Q} \\
\%\end{array}$ & Measurement & $\begin{array}{c}\dot{Q}_{w} \\
\mathrm{~kW}\end{array}$ & $\begin{array}{c}\delta \mathrm{Q} \\
\%\end{array}$ \\
\hline HE-1/1/H4-S1 & 11.23 & 1.8 & HE-1/1/H4-S2 & 11.75 & 6.5 \\
\hline HE-1/2/H4-S1 & 23.08 & 2.1 & HE-1/2/H4-S2 & 24.15 & 6.8 \\
\hline HE-1/3/H4-S1 & 34.73 & 1.9 & HE-1/3/H4-S2 & 36.60 & 7.4 \\
\hline HE-1/4/H4-S1 & 9.95 & 2.4 & HE-1/4/H4-S2 & 10.26 & 5.6 \\
\hline HE-1/5/H4-S1 & 19.94 & 2.7 & HE-1/5/H4-S2 & 20.66 & 6.4 \\
\hline HE-1/6/H4-S1 & 29.84 & 2.5 & HE-1/6/H4-S2 & 31.12 & 6.9 \\
\hline
\end{tabular}

This hypothesis $\mathrm{H} 4$ has been confirmed, as it can be seen in Table 6. Better results have been obtained during the $\mathrm{S} 2$ measurements.

\subsection{Verification of the $\mathbf{H 5}$ hypothesis}

In many cases a heat exchanger's user cannot change the media flow conditions (due to different limitations). The authors postulate that in such cases some improvement may be achieved by installing a heat exchanger with special ribbing structure - the ribbing density should be fitted to certain media flow conditions. The general idea of hypothesis $\mathrm{H} 5$ is that extending the heat transfer surface in the area where a medium flow is more intensive would also intensify the heat transport.
The ribbing structure could only be designed properly if one knows the media flow structure (velocity field at the exchanger's inlet). In this connection the authors planned the following analysis procedure:

- measurements for standard designed heat exchangers (with uniform ribbing structures),

- design of the special ribbing structures based on the measured fields of the air velocity at the exchangers' inlet,

- simulating the performance of the special heat exchangers in order to predict potential changes of their efficiency - this step was done using the in-house computer code HEWES and allowed to make the final decision of constructing these special heat exchangers,

- measurements for specially designed heat exchangers.

The hypothesis No. 5 has been verified for the HE-2 and HE-3 heat exchangers. These heat exchangers have a uniform structure of fins and have been chosen for the analysis due to technical possibilities of making special versions of these units. The first step was to perform the reference measurements (Table 7) and localize the areas of intensive air inflow (Figs. 7 and 8).

The measurements done for the specially designed heat exchangers have been analyzed the same way as for the standard units. The heat transfer rates have been computed as the water enthalpy drop and were next compared with the heat transfer rates for the heat exchangers with uniform ribbing structures (see the last column in Table 7). The relative differences between experimental data and numerical predictions were also calculated. The selected outcomes of this analysis are gathered in Table 8.

Table 7. Selected results of the reference measurements for the HE-2 and HE-3 units.

\begin{tabular}{|c|c|c|c|c|}
\hline $\begin{array}{c}\text { Measurement } \\
\text { No. }\end{array}$ & $\begin{array}{c}V_{w} \\
\mathrm{dm}^{3} / \mathrm{min}\end{array}$ & $\begin{array}{c}T_{w, \text { in }} \\
{ }^{\circ} \mathrm{C}\end{array}$ & $\begin{array}{c}T_{w, \text { out }} \\
{ }^{\circ} \mathrm{C}\end{array}$ & $\begin{array}{c}\dot{Q}_{w} \\
\mathrm{~kW}\end{array}$ \\
\hline HE-2/1 & 16.9 & 49.3 & 45.0 & 5.07 \\
\hline HE-2/10 & 16.9 & 68.9 & 60.8 & 9.55 \\
\hline HE-2/19 & 16.1 & 87.4 & 74.4 & 14.61 \\
\hline HE-2/2 & 22.3 & 50.5 & 46.5 & 6.22 \\
\hline HE-2/11 & 22.5 & 69.7 & 62.7 & 10.99 \\
\hline HE-2/20 & 22.1 & 88.3 & 78.3 & 15.42 \\
\hline HE-3/3 & 28.8 & 49.8 & 45.4 & 8.84 \\
\hline HE-3/12 & 28.8 & 69.2 & 61.4 & 15.68 \\
\hline HE-3/21 & 28.1 & 88.5 & 77.1 & 22.35 \\
\hline HE-3/6 & 28.3 & 50.4 & 46.4 & 7.90 \\
\hline HE-3/15 & 27.9 & 70.4 & 62.8 & 14.80 \\
\hline HE-3/23 & 27.3 & 89.7 & 77.8 & 22.67 \\
\hline
\end{tabular}

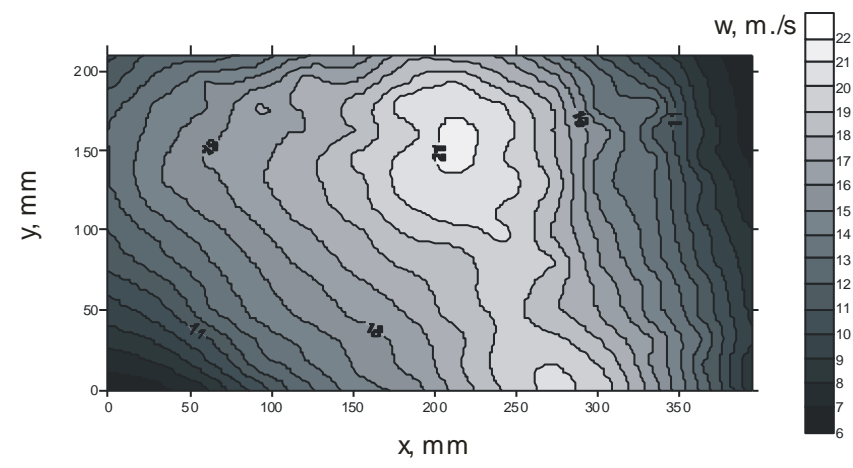

Figure 7. Distribution of the air velocity at the inlet for the HE-2/1 measurement. 


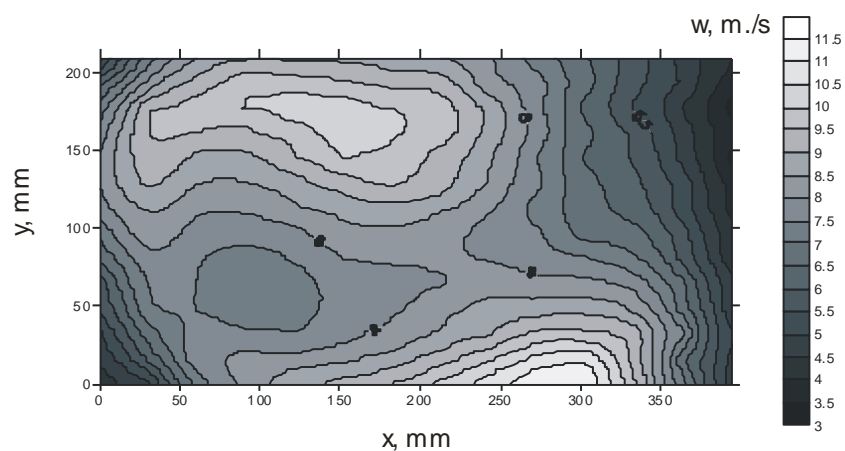

Figure 8. Distribution of the air velocity at the inlet for the HE-3/4 measurement.

Looking at the values in Table 8 one may note that for the HE-2M heat exchangers the situation is worse or slightly better than for the uniformly ribbed heat exchanger HE-2. The results of experiments for the HE-3M heat exchanger show some enhancement of its performance in comparison with the HE-3 unit. Experimental data allow confirming the hypothesis only for the two-row heat exchanger (HE-3M). The results obtained for the HE-2 unit are somewhat controversial. The most important reason of this situation is fact that the distribution of the air velocity inflowing to the modified units is different from the one taken into account while designing the special ribbing structure. This is due to a change of hydraulic resistance in the flow.

Table 8. The H5 hypothesis verification - selected results.

\begin{tabular}{|c|c|c|c|}
\hline \multirow{2}{*}{$\begin{array}{c}\text { Case } \\
\text { No. }\end{array}$} & $\begin{array}{c}\text { Standard } \\
\text { heat } \\
\text { exchanger }\end{array}$ & $\begin{array}{c}\text { Modified } \\
\text { heat } \\
\text { exchanger }\end{array}$ & $\begin{array}{c}\text { Relative } \\
\text { difference } \\
\text { (standard- } \\
\text { modified) }\end{array}$ \\
\cline { 2 - 4 } & $\begin{array}{c}\dot{Q}_{w} \\
\mathrm{~kW}\end{array}$ & $\begin{array}{c}\dot{Q}_{w} \\
\mathrm{~kW}\end{array}$ & $\delta \mathrm{Q}, \%$ \\
\hline $\mathrm{HE}-2-2 \mathrm{M} / 1$ & 5.07 & 5.00 & -1.4 \\
\hline $\mathrm{HE}-2-2 \mathrm{M} / 10$ & 9.55 & 9.34 & -1.8 \\
\hline $\mathrm{HE}-2-2 \mathrm{M} / 19$ & 14.61 & 14.73 & 0.8 \\
\hline $\mathrm{HE}-2-2 \mathrm{M} / 2$ & 6.22 & 6.21 & -0.2 \\
\hline $\mathrm{HE}-2-2 \mathrm{M} / 11$ & 10.99 & 11.15 & 1.5 \\
\hline $\mathrm{HE}-2-2 \mathrm{M} / 20$ & 15.42 & 15.71 & 1.9 \\
\hline $\mathrm{HE}-3-3 \mathrm{M} / 3$ & 8.84 & 9.34 & 6.0 \\
\hline $\mathrm{HE}-3-3 \mathrm{M} / 12$ & 15.68 & 16.42 & 4.5 \\
\hline $\mathrm{HE}-3-3 \mathrm{M} / 21$ & 22.35 & 23.31 & 6.3 \\
\hline $\mathrm{HE}-3-3 \mathrm{M} / 6$ & 7.90 & 8.72 & 10.4 \\
\hline $\mathrm{HE}-3-3 \mathrm{M} / 15$ & 14.80 & 15.76 & 6.5 \\
\hline $\mathrm{HE}-3-3 \mathrm{M} / 23$ & 22.67 & 23.98 & 5.8 \\
\hline
\end{tabular}

\section{Conclusions}

The results presented here from experimental analyses do not allow for a full and unambiguous verification of the assumed hypotheses.

All performed analyses partially confirmed the first assumed hypothesis. Analyses of the experimental results have shown a visible growth of the total heat flux transferred in the considered exchanger. This growth ranges from 2 percent (for wire net filters) to about 9 percent (perforated metal sheet filters). For some cases the growth remains in the measurement uncertainty limits, so it cannot be unambiguously interpreted. Based on the received results this hypothesis seems to be reliable. Further investigations are necessary to fully prove this assumption using experiments (measurements with different filters).
The results received from the realized research cannot be used for proper verification of the second hypothesis. The air inflow blocking causes changes in the pressure drop and also changes the fan working point. The plates used for this blocking are the reason of local vortices and also they disturb the air inflow in the neighboring measuring fields. These phenomena are probably the reasons of the observed decrease in the heat flow rates. The values of these changes are small - below the measuring errors - making proper interpretation difficult.

The results obtained while verifying the $\mathrm{H} 3$ hypothesis could not be used as the base for evaluation of this hypothesis. The changes of the total heat transfer rates are relatively small and remain in the bands of measuring errors. The verifying measurements were strongly limited by technical problems. The degree of turbulence needs additional analysis. The authors have elaborated a CFD numerical model of the experimental stand with the spiral insertion for assessment of the turbulence degree and optimization of the shape of insertions.

According to the received results the hypothesis $\mathrm{H} 4$ has been partially confirmed. This subject needs further research of course, but it is very promising, because the realization of such an approach is technically easy and cheap.

Summarizing, it should be noted that the best solution is assuring the uniform inflow of media to the heat exchanger, but this cannot be achieved in many cases. In such situations application of special ribbing structures or installation of insertions directing the flow in the proper regions of the heat exchanger may be considered.

\section{Acknowledgements}

This work was sponsored by the Ministry of Science and Higher Education, Grant No. N N512 458836. Technical support of the GEA Heat Exchangers Company is also acknowledged.

\section{Nomenclature}

$\mathrm{c}_{\mathrm{p}} \quad$ - specific heat capacity at constant pressure, $\mathrm{J} /(\mathrm{kg}$ K)

$\dot{m}$ - mass flow rate, $\mathrm{kg} / \mathrm{s}$

NU - non-uniformity parameter

$\dot{Q} \quad$ - heat transfer rate, W

$T$ - temperature, ${ }^{\circ} \mathrm{C}$

$V \quad$ - volumetric flow rate, $\mathrm{m}^{3} / \mathrm{s}$

$\rho \quad$ - mass density, $\mathrm{kg} / \mathrm{m}^{3}$

Subscripts

$$
\begin{array}{cll}
\text { a } & - & \text { Air } \\
\text { in } & - & \text { Inlet } \\
\text { out } & - & \text { Outlet } \\
\text { w } & - & \text { Water }
\end{array}
$$

\section{References}

Anjun, J., Rui, Z., Sangkwon J. (2003). Experimental Investigation of Header Configuration on Flow Maldistribution in Plate-Fin Heat Exchanger. Applied Thermal Engineering, 23, 1235-1246.

Berryman, R. J., Russell, C. M. B. (1987). The Effect of Maldistribution of Air Flow on Aircooled Heat Exchanger Performance, In: Maldistribution of Flow and Its Effect on Heat Exchanger Performance, J.B. Kitto \& J.M. Robertson (Eds.), ASME Htd, Vol. 75. 
Bury, T. (2012). Impact of a Medium Flow Maldistribution on a Cross-flow Heat Exchanger Performance. In: Heat Exchangers - Basic Design Applications. J. Mitrovic (Ed.), InTech, Rijeka, Croatia.

Bury, T., Składzień, J., Hanuszkiewicz-Drapała, M. (2009). Experimental and Numerical Analyses of a NonUniform Agents Flow Impact on a Finned Cross-Flow Heat Exchanger Effectiveness. Proceedings of the 22nd International Conference on Efficiency, Cost, Optimization, Simulation and Environmental Impact of Energy Systems - ECOS 2009, Foz do Iguacu, Parana, Brasil, on $C D$.

Bury, T., Składzień, J., Widziewicz K. (2010). Experimental and numerical investigations of impact of a medium flow modelling on a cross-flow ribbed heat exchanger efficiency. Proceedings of the 2nd Conference on Modern Energy Technologies, Systems and Units, Kraków, Poland.

Hoffmann-Vocke, J., Neale, J., Walmsley, M. (2009). Flow Profiles on the Fin Side of a Plate Fin-And-Tube Heat Exchanger Experiencing Gross Flow Maldistribution. Proceedings of 7th World Conference on Experimental Heat Transfer, Fluid Mechanics and Thermodynamics, Kraków, Poland, on CD.

Hoffmann-Vocke, J., Neale, J., Walmsley, M. (2011). The Effect of Inlet Conditions on the Air Side Hydraulic Resistance and Flow Maldistribution in Industrial Air Heaters. International Journal of Heat and Fluid Flow, $32,834-845$.

Lalot, S., Florent, P., Lang, S. K., Bergles, A. E. (1999). Flow Maldistribution in Heat Exchangers. Applied Thermal Engineering, 19, 847-863.

Lee, K. S. \& Oh S. J. (2004). Optimal Shape of the MultiPassage Branching System in a Single-Phase ParallelFlow Heat Exchanger. International Journal of Refrigeration, 27, 82-88.

Luo, X. Roetzel, W. Lüdersen, U. (2001). The Single-Blow Transient Technique Considering Longtitudinal Core
Conduction and Fluid Dispersion. International Journal of Heat and Mass Transfer, 44, 121-129.

Meyer, C.J., Kröger, D.G. (1998). Plenum Chamber Flow Losses in Forced Draught Air-Cooled Heat Exchangers. Applied Thermal Engineering, 18, 875-893.

Mueller, A. C. (1987). Effects of Some Types of Maldistribution on the Performance of Heat Exchanger. Heat Transfer Engineering, 8, 75-86.

Piątek, R. (2003). Thermal Analysis of Plate Fin and Tube Heat Exchanger with Unequal Inlet of Media (Doctoral Dissertation), Institute of Thermal Technology, Silesian University of Technology, Gliwice. (in Polish)

Rao, B. P., Sunden, B., Das S. K. (2006). An Experimental Investigation of the Port Flow Maldistribution in Small and Large Plate Package Heat Exchangers. Applied Thermal Engineering, 26, 1919-1926.

Shaji, K., Das S. K. (2010). The Effect of Flow Maldistribution on the Evaluation of Axial Dispersion and Thermal Performance During the Single-Blow Testing of Plate Heat Exchangers. International Journal of Heat and Mass Transfer, 53, 1591-1602.

Srihari, N., Das S. K. (2008). Transient Response of MultiPass Plate Heat Exchangers Considering the Effect of Flow Maldistribution. Chemical Engineering and Processing: Process Intensification, 47, 695-707.

Srihari, N., Rao, B.P., Sunden, B., Das S. K. (2005). Transient Response of Plate Heat Exchangers Considering Effect of Flow Maldistribution. International Journal of Heat and Mass Transfer, 48, 3231-3243.

Wen, J., Li, Y. (2004). Study of Flow Distribution and Its Improvement on the Header of Plate-Fin Heat Exchanger. Cryogenics, 44, 823-831.

Zhang, L. Z. (2009). Flow Maldistribution and Thermal Performance Deterioration in a Cross-Flow Air to Air Heat Exchanger With Plate-Fin Cores. International Journal of Heat and Mass Transfer, 52, 4500-4509. 